\title{
The Value Exploration on the Digital Technology to the Cultural Database Construction of Bashu Folk Music Culture
}

\author{
Xiaoan Zeng \\ School of Music, China West Normal University, Nanchong Sichuan, 637009, China
}

Keywords: Digital Technology, Bashu Folk Music Culture, Cultural Database, Value Exploration.

\begin{abstract}
Bashu folk music culture has a long history, and covers a wide range. It is an important part of the traditional culture in Bashu. However, there are still a lot of problems in the classification of Bashu folk music, such as the ambiguous concept and the inaccurate defining, etc. Also, it is deficient in the screenings and application of music service for dancers. However, Various kinds of music editing software provided by digital technology has contributed a lot to the construction of Bashu folk music cultural database by its vivid expression and application value. Based on the value of digital technology to the construction of Bashu folk music cultural database, this article clarifies the traditional classification of Bashu folk music and the basis of the support of digital technology to the construction of Bashu folk music cultural database respectively. In the end, this article also explores the application value and prospects of digital technology to the classification of Bashu folk music.
\end{abstract}

\section{Introduction}

Bashu folk music culture is very profound, and it is an excellent part of Chinese traditional culture. However, it has always been a difficult problem for the classification of Bashu folk music. As the coming of information age in our country, it is a new social trend to combine Bashu folk music and digital technology, which greatly promotes the folk art and cultural heritage protection process in our country.

Moreover, digital technology plays an important role in the construction of Bashu music cultural database, and it increases the feasibility of the implementation of music digital classification. Once the systematical Bashu music cultural database is established successfully, then the excellent Bashu folk music can be permanently stored in the database, which will be conducive to the spread of Bashu folk music culture to the world and let more people understand the Chinese excellent traditional music culture and the spirit of China.

\section{Classification of Bashu folk music}

Bashu folk music is of various style and in different forms. Also, it is rich in humanistic background. The current styles of genres of it contain folk songs, Quyi, opera and instrumental music,etc. Besides, there are different branches under each type, which constitutes the rich and colorful Bashu folk music culture together.

\subsection{Folk song}

According to different genres, Bashu folk songs can also be divided into different mountain songs, custom songs, nursery rhymes, work songs, minor and so on. According to the different singing method, the mountain songs can be classified to high-pitched tune mountain songs, flat-pitched tune mountain songs and low-pitched tune mountain songs. According to different structure, it can be classified to five-sentence ballad, eight-sentence ballad and Chuan haozi. And other classifications according to different lyrics. Then, it comes to the work songs, which is also known as Shaozi. It can be divided to boatman work songs, salt man work songs, etc, according to the different kinds of labors. And the minor, is easily to be classified to urban minor and agricultural minor. What's more, the custom songs, contain the custom wedding songs, sad songs and light tones, etc. The last one will be 
nursery rhyme, which can be classified to children's songs, mainly children's songs, teenager rhyme, and the "doll".

\subsection{Quyi and opera}

In the long history of Bashu folk music culture, it is worthwhile to mention Bashu opera and folk arts. It can be said that they are the ones with the most types and styles of folk music.they have the long history and are of great ethnic characteristics. Quyi contains the Sichuan resonance, Sichuan dulcimer, singing with playing the instruments together, flower drum, Shanshu, etc. While opera includes the branches of Sichuan opera, Quju, lantern opera and so on. All the branched have its own special meanings and culture background, and represent people's passion and understanding to life and the society, which contains rich delicate feelings and ideas, and it is worthwhile for us to taste.

\subsection{Instrumental music}

Bashu folk music not only refers to the folk songs or opera that have been written well, but also includes the instrumental music. Bashu instrumental music mainly contains ensemble of wind and percussion instruments, drum music as well as other solo and string and bamboo flute music played by all kinds of instruments, etc. And these music only played by instruments is often more attractive.

\section{The basis of the support of digital technology to the construction of Bashu folk music cultural database}

\subsection{The goal of database construction}

Bashu folk music cultural database is established based on the classification of Bashu folk music. With the principle of database, it manages the data information required by the Bashu folk music culture study together, such as text, image, audio, video and so on, which forms the sub database shown as bellow: the region database, culture database, image resource database, tone database, video database, rhythm database,complete music scores browsing database and so on. The structure of database construction adopts the basic three-tier architecture system of the browser/web server,and the advantage of which is to directly connect the campus network with the education research network in China. After Bashu folk music cultural database is established, the serving objectives of Bashu folk music cultural database are mainly aimed at the scholars of Chinese traditional folk music and other educational experts in this field, so that they can have the deep research and survey to Bashu and the Chinese traditional folk music culture conveniently, and make the rich and excellent traditional folk music culture in China be popular at home and abroad, then more and more people in the world will know China, understand China and recognize China.

\subsection{The theoretical basis of database construction}

The theoretical basis of database construction is to organize and classify the traditional folk culture. There are two main types of classification: one is based on the data type, and the other is classified according to the different cultural types, the music rhythm and the melody. It aims to systematically and systematically integrate these scattered and different forms of Bashu music information and audio and video.

The Classification according to data types. Factors, such as region culture, timbre, music scores, picture resources, rhythm, audio and video etc, are concluded in the category of relational databases. Of course, the file-type database and multimedia database are included as well. Here, it is important to emphasize the connection and distinction between relational and file-type databases. Relational database is focused more on data to look up information from the horizontal and vertical angles, and then the data resources will be ordered, combined and connected to an orderly and unified database. In contrast, the file-type database emphasizes more on the storage of many of the same data information into different locations in the database. In this way, the two kinds of databases complement each other and have its own advantages, which improves the efficiency of data storage 
and scalability. Classified according to the different cultural types, the music rhythm and the melody. As as an important part of the excellent Chinese traditional folk culture, Bashu folk music culture vividly describes people's living environment, historical development, customs and social culture in Bashu. The special Bashu folk music culture is formed by different elements, such as the long historical background of Bashu music culture in various regions, diversified music style and rhythm and so on. Bashu is a vast territory, and people in all regions have their own habits. Therefore, there are many types and styles of music culture. As for these precious and historic cultural heritages and intelligent crystallization, we need to preserve them permanently, and organize and classify them well. With the aid of digital technology, a great Bashu folk music cultural database must be established to store all these folk music of different styles, different melodies and geographical background.

\subsection{Taking data warehouse technology as the technical basis for the construction of Bashu folk music cultural database}

It is well known that the data warehouse technology is a kind of organization form used by computers to store data information in the Internet industry. And it is also a data collection which is thematic and relatively stable, and can reflect the culture and history. The application of data warehouse technology is to effectively gather those operational data to a unified data environment, so as to provide technical support for decision-making data and better assist the implementation of the management decision. Data warehouse technology is different from other types of operational database, and it is oriented to the analytical data processing, which can efficiently integrates multiple heterogeneous data sources and divide them into different groups according to different themes. These data sources also contain the historical data, because data warehouse technology generally has no permissions to overwrite data stored in the data warehouse.

Based on the implementation of the data warehouse technology, Bashu folk music cultural database application system will carry on the highly centralized management to those multimedia resources distributed by the differences of region culture or data types, such as image, audio and video and complete music scores, tone rhythm and so on, and then the systematical and effective information will be formed through the scientific arrangement and orderly classification. All information will be presented in the form of a document page through the Internets technical means, so that the manager can update and manage the data. The Bashu folk music cultural database based on the data warehouse technology can automatically collect and maintain the researching website involved the study of bashu folk English culture, which is very convenient for researchers of folk music culture, and promotes the resource sharing and information exchange.

\section{The application prospect and value of digital technology in the classification of Bashu folk music}

Classify Bashu folk music according to the cultural type and musical system, and then use the digital technology, such as music score printing software, audio software, automatic accompaniment software etc, to record and edit the Bashu folk music, which greatly promotes the construction process of Bashu folk music cultural database, and explores the application prospect and value of digital technology in the Bashu folk music.

\subsection{The sorting function of music score printing software}

The music score printing software is specially created for the composer to print music score, and it satisfies a lot of composers who want to show the beautiful music score to the public. This kind of music score printing software only needs to print out a kind of music score, which can be used for the transformation and transmission to notes, staff and simplified lines controlling notes. This makes it possible to avoid confusion caused by the various music editing software on the market. At the same time, music score printing software obtains very comprehensive music symbols, which can not only print, but also help the creation of Bashu folk music chords and staff. And the operation is simple and easy to store. There are also a lot of other application. 


\subsection{Voice edit function of audio source software}

The biggest characteristic of voice edit software is to be able to to display a variety of tone information of electronic synthesizer in the intuitive graphical way through the computer, which can help the operator directly adjust and modify the synthesizer tone on the computer. After modification, it can be directly stored on computer disks or the U disk carried. Due to the direct contact between the classification of Bashu folk music and the different tunes and timbres of folk music in different regions of Bashu, the user can screen hundreds of voices from the sound source on the voice edit software, and the quality of sound source can directly decide the quality of voice.

Software operators only need to provide some pictures of instrument information, and then find the tones in different tone area on the MIDI keyboard, then the part of the compose or the whole compose can be played. As the arrival of the digital age, it provides a very good platform for the inheritance and protection of folk music culture. Also with the continuous efforts of science and technology workers, more and more folk musical instruments and voices are collected and added to the repository of sound source software .

\subsection{The creation function of automatic accompaniment software}

The automatic accompaniment software is actually a kind of "idiot" type music software, which is very easy to operate. And the operation procedure is very simple, which only involves two basic processes. One is the input chord function, and the other is to select the music style. The operator only needs to follow the instructions of the software, and then operate the next step. Now the relatively well-known automatic accompaniment software are Band - In - A - Box, Super Jam, and so on. These software contain a large number of different music styles. but due to the same basic principle,the users will input the chord of the compose according to the rhythm firstly, then they will match the corresponding styles to each compose with letter notation. Then, the users' job is done, and the rest will be synthesized and created to a compose by the computer automatically.

All types of music style of Bashu folk music can be edited by automatic accompaniment software, only to match with the corresponding chord and music style, and then to modify. So, a complete song can be composed. In addition, we can make full use of the digital technology to classify different styles of Bashu folk music according to the different speed and tempo, and then record theorem the multimedia database. This database only belonged to Bashu folk music culture is classified strictly according to the regional culture characteristic. And it is concise and clear, and has clear level, which is very convenient for people to find all kinds of data and audio and video of Bashu folk music culture quickly.

\section{Conclusion}

With the continuous development of science and technology in modern society, all walks of life in our country begin to merge with the Internet and accept the Internet. If any industry wants the long-term developments, then it must follow the trend of social development. In order to inherit and protect the Bashu folk music culture well, the construction of database is of important meaning and value. As the coming of digital era, it provides a good platform and technical ways for the construction of Bashu folk music cultural database, which is not only benefit to the classification and sorting of different styles of Bashu folk music, but also promote to the storage and preserve of the excellent national culture. And people can enjoy the traditional folk music at anytime and everywhere.

\section{Acknowledgement}

This research was financially supported by Yingcai project of Xihua Normal University Research on Bashu folk music culture (Project no. : 17YC538); The invocation team of Xihua Normal University Research on Bashu folk music culture and database construction (Project no. : 
CXTD2016-8).

\section{References}

[1] Wang Haiyan, The value of digital technology to the construction of national folk dance music database in China, Design art research, 2013-12-15.

[2] Ge Chunxian, The digital construction idea of music appreciation teaching materials in universities, Technology and publication, 2015-08-08.

[3] Gaoyan,Music college digital library information resources construction, modern library intelligence technology, 2002-09-25.

[4] Yangsi, Tthe value of digital technology to the construction of Chinese folk arts and crafts database, Invention and innovation (education informationization), 2017-01-15.

[5] Zhuoyi,The transformation of traditional music industry and its development strategy -- based on digital technology, Journal of Minnan Normal University (Philosophical social science edition), 2015-03-15. 